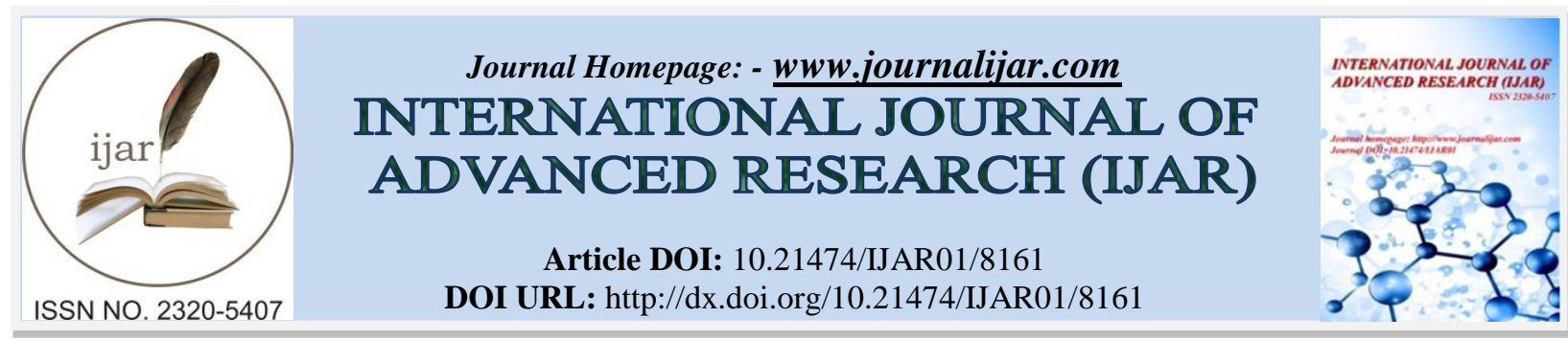

RESEARCH ARTICLE

\title{
DEVELOPMENT OF POLYMERIC COMPOSITES BY USING REACTIVE MELT BLENDING PROCESS: A MODERN AND ADVANCED TECHNOLOGY.
}

\begin{abstract}
Aftab Alam.
G.N.D. Institute of Technology, Rohini, Delhi-110089 (India).

\section{Manuscript Info}

Manuscript History

Received: 04 October 2018

Final Accepted: 06 November 2018

Published: December 2018

Keywords:

Polymer, Composites, Hybird Composties, Twin Screw Extrduer, Nano particle, Natural fibres.

Abstract

Polymeric hybrid composites consist of the system in which one type of reinforcement is mixed in a different matrix or two or more reinforcements are present in a single polymer matrix. The need of sustainability and green environmental concern leads to the development of hybrid polymeric composites reinforced with one or more reinforcement of nanomaterials and natural fibres. This mixing results with the reduction in water uptake capacity and improvement in mechanical properties.

The cost effectiveness and dispersion of nanomaterials with natural fibres are some limiting factors in the development of these advanced composites. The synthesis of polymers based hybrid composites by reactive melt blending technology, using co-rotating twin screw has been developed into a technology of next level.
\end{abstract}

Copy Right, IJAR, 2018,. All rights reserved.

\section{Introduction:-}

Polymers are very attractive materials. They offer many advantages like low density and can be converted into complex 3D shaped very easily as compared to metals and other existing engineering materials. Synthetic polymers are resistant to microbial attack because of their hydrophobic character. With time, stability and durability of polymers have been improved and hence this material is become as a synonym for material being resistant to many environmental influences. The properties are very important factor when using the material for packaging/automobile sector to save weight, melting temperatures and transportation of goods. The production and consumption of polymers has increased significantly with a rate of almost $12 \%$ every year since 1950 . In 2017 , the worldwide polymer production has reached 370 million ton per annum [1].

The new class of material which offer outstanding properties has been identified as the combination of polymers reinforced with fibers i.e. composites. The composites materials defined as the material consist of two or more distinct phase or materials, which when combined together on macroscopic scale gives a new material with entirely different properties (better and more stronger and tougher i.e. more durable) from the individual constituents [2,3].

The matrix of most common traditional composites (PMC) consists of thermoplastic or thermoset polymers. On the basis of reinforcement composites may be further classified into three different classes i.e. particle, reinforced or structural composites. The use of natural fibers as reinforcing material in polymers can provide many advantages and are viable alternative to inorganic fillers like glass fiber which may creates several serious health problems to the worker and more tool wears because of their hardness and corrosive nature. Natural fibers are renewable and sustainable in nature and are biodegradable in nature. They offer outstanding properties as reinforcing materials like low density, high specific properties and more importantly non-abrasive in nature (increases production/running life

Corresponding Author:-Aftab Alam.

Address:-G.N.D. Institute of Technology, Rohini, Delhi-110089 (India). 
of product machinery) permits a high volume of filling in the hybrid composites. They are recyclable and can be easily converted into thermal energy through combustion, without leaving residue [4,5].

Now more than ever, the industries like construction, automotives, packaging are under increasing pressure to meet higher environmental and performance demands at competitive costs. Using natural fibers with polymers based on renewable resources will allow many of these issues to be solved. The renewable and sustainable based polymeric hybrid composites are continuously being developed by scientists worldwide for many applications like automobile, construction, packaging etc. Table no. 1 shows comparison between glass fibres and natural fibres. This table clearly indicated that some natural fibres are far better in term of specific modulus and strength, when compared with most common reinforcement of composites or fibre reinforced plastics i.e. glass fibers [6,7]. Natural fibres composites with polyolefins offer good performance at lower prices as they belongs to commodity polymers (i.e. polymers with low price and high uses) creating huge potential to replace other competing materials in the market like automotive, construction, packaging and consumer products [8-11].

Table 1:-

\begin{tabular}{|c|c|c|c|c|}
\hline Fibre & Density $\left(\mathrm{gm} / \mathrm{cm}^{3}\right)$ & E-Modulus (GPa) & $\begin{array}{ll}\begin{array}{l}\text { Specific } \\
\text { (Mod/Den) }\end{array} & \text { Modulus } \\
\end{array}$ & $\begin{array}{l}\text { World Production }\left(1^{3}\right. \\
\text { ton }\end{array}$ \\
\hline E-glass & 2.55 & 73 & 29 & -- \\
\hline Flax & 1.44 & $60-80$ & $43-57$ & 970 \\
\hline Jute & 1.46 & $10-30$ & $7-21$ & 2300 \\
\hline Sisal & 1.33 & 38 & 29 & 375 \\
\hline Hemp & 1.48 & 70 & 47 & -- \\
\hline
\end{tabular}

Nano-materials are recently also considered as high potential filler materials for the development of nanocomposites. The nano scale materials are usually free from all defects and hence, the additions of nano-materials to the synthetic polymer gives improved properties substantially are mechanical properties like strength, elastic modulus and dimensional stability, thermo-mechanical properties and permeability towards gases, water and hydrocarbons [12-14].

The incorporation of many fibers (Natural and/or Synthetic) and nano-particle as reinforcement in a single polymer matrix results in the development of hybrid composite. Hybrid composites are usually designed and processed by the incorporation of a synthetic fiber and nature fiber in a matrix. The result properties of hybrid composites are depends on the properties of individual reinforcements leads to synergetic performance [15-18]. The combination of natural fibres with nano-material has encouraging results, which leads to reduction in water absorption, thickness swelling and improvement in impact strength and mechanical properties of the hybrid composites. The properties of resultant hybrid composites will be govern by the dispersion, compatability, orientation and aspect ratio of the of reinforcement in matrix of the composites. However, several methods have been established to supplement these disadvantages by the introduction of coupling agent and/or various surface modification techniques. The surface of the natural fibres can be modified by physical, mechanical and chemical methods [19,20].

\section{Processing of Hybrid composites:}

This paper deals the requirement of processing of polymeric composites and nano-composites, and lights the techniques that can be applied in reactive melt extrusion processes using co-rotating twin screw extruders.

The thermoplastic processing of polymers is mainly performed by extrusion, one of the most important polymer processing techniques. Extrusion process allows melting of a polymer due to supply of heat and energy input caused by friction between the screws, the plastic melt, becomes formable and is passed through the die of desired shape and size. During the whole processing the melt is compressed, mixed, plasticized, homogenized, chemically reactive blending [21].

The polymer based composites are widely used in the plastic industries like aero space, automobile, construction etc. The trend in the plastic industries in recent years has been towards the incorporation of fillers and additives to get 
highest level of strength and reduction in weights i.e. specific strength/modulus. This has been forced by the market which has demanded higher quality, lower cost, increasing safety and in general terms more arduous applications for polymeric composites, which leads to the development of hybrids composites i.e. reinforcement of two or more materials in polymer matrix.

The manufacturer of Twin Screw Extruders have developed a range of machines and/or techniques to enables the handling of high level of loading of fillers and fibres to be processed. Their aim has been to produce the utmost quality composites, with most efficient energy utilization in the lowest possible time i.e. using hardware of minimum size and with reduced cost.

The polymeric hybrid composites might contain up to $50 \%$ of fillers together with $1-5 \%$ nano-materials and processing aids. These highly loaded polymeric formulations set critical demands on the compounding process.

\section{Dispersion of Reinforcement materials in polymeric matrix}

This is very useful to consider the overall process of compounding of multi-phase systems, which are quite distinct in nature. The reinforcement especially nano-materials are normally small in particle size, and in dry state, the filler powder can contain some aggregates which attached to the other aggregates and/or powder and forming agglomerates. The first stage involved with the wetting of these aggregates and agglomerates. The liquid system (like polymer melt, and additives), can be characterized by viscosity, and solubility of the different components of the system. The miscible system can be homogenized on a molecular scale, while immiscible system will shows a two phase structure and their miscibility will depends on nature of phase and the mechanical process used.

After proper wetting of the reinforcements some form of mechanical energy is required to bring the complete separation i.e. dispersion of particle in polymeric matrix. Once the wetting the surface and breakdown of aggregates/agglomerates i.e. complete dispersion, this state must be then maintained, since the particle have a tendency to reduce the surface area. In polymeric system the dispersion is usually stabilized by the high viscosity of the melt and surface active additives like silanes and stearates. These additives also provides added benefits like lubrication which results with reduction in melt temperature and friction between the different components of the composites system.

\section{Co-Rotating Twin Screw Extruder:}

The twin screw extruders were developed to overcome limitations of the single screw extruder. The mainly two types i.e. co-rotating and counter-rotating twin screw extruders have been available in the market. In this paper our discussions are focused on co-rotating intermeshing extruders (Figure1), in which material travelling round the screw is transferred from one screw to the other in a figure of eight pattern. This result in a uniform shear and mixing, and thus co-rotating twin screw extruders are generally used for mixing and compounding, blending, and reactive blending of the polymeric systems. Nowadays co-rotating twin screw extruders are available in segmented barrel and screw form. This allow both the barrel and screw configurations to be specified to match the process requirement i.e. shear rate and residence time.

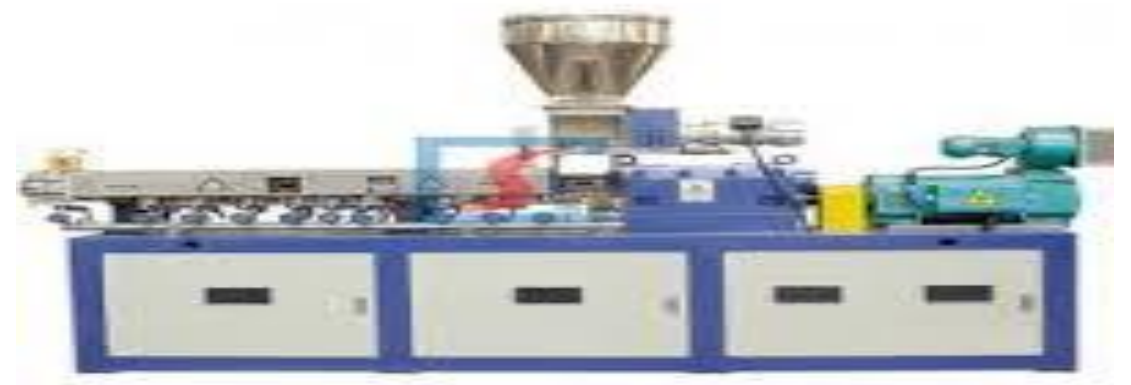

Figure 1:-Lab scale Twin screw extruder 


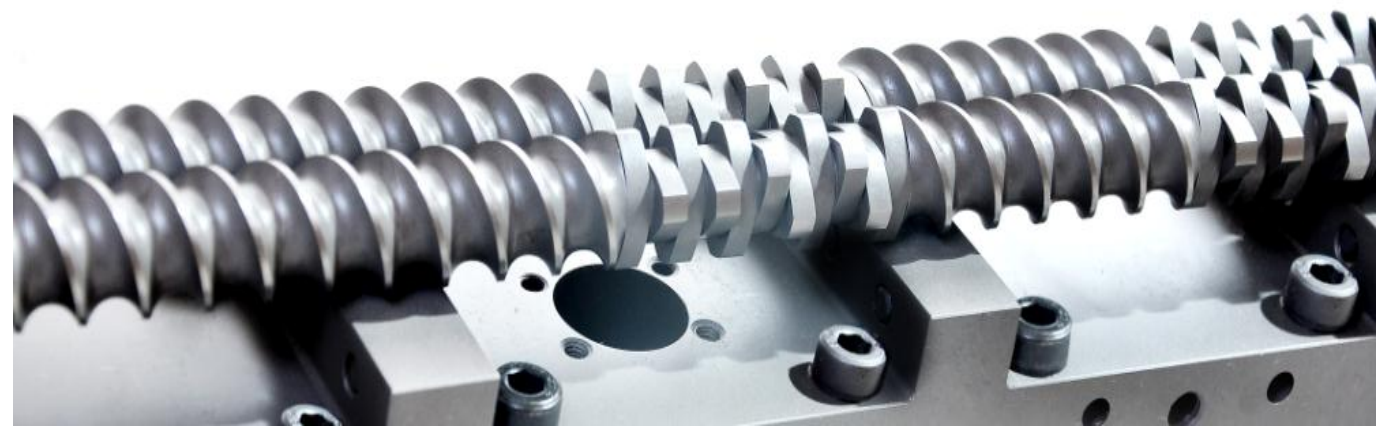

Figure 2(a):-Segment twin screw with conveying and kneading system.

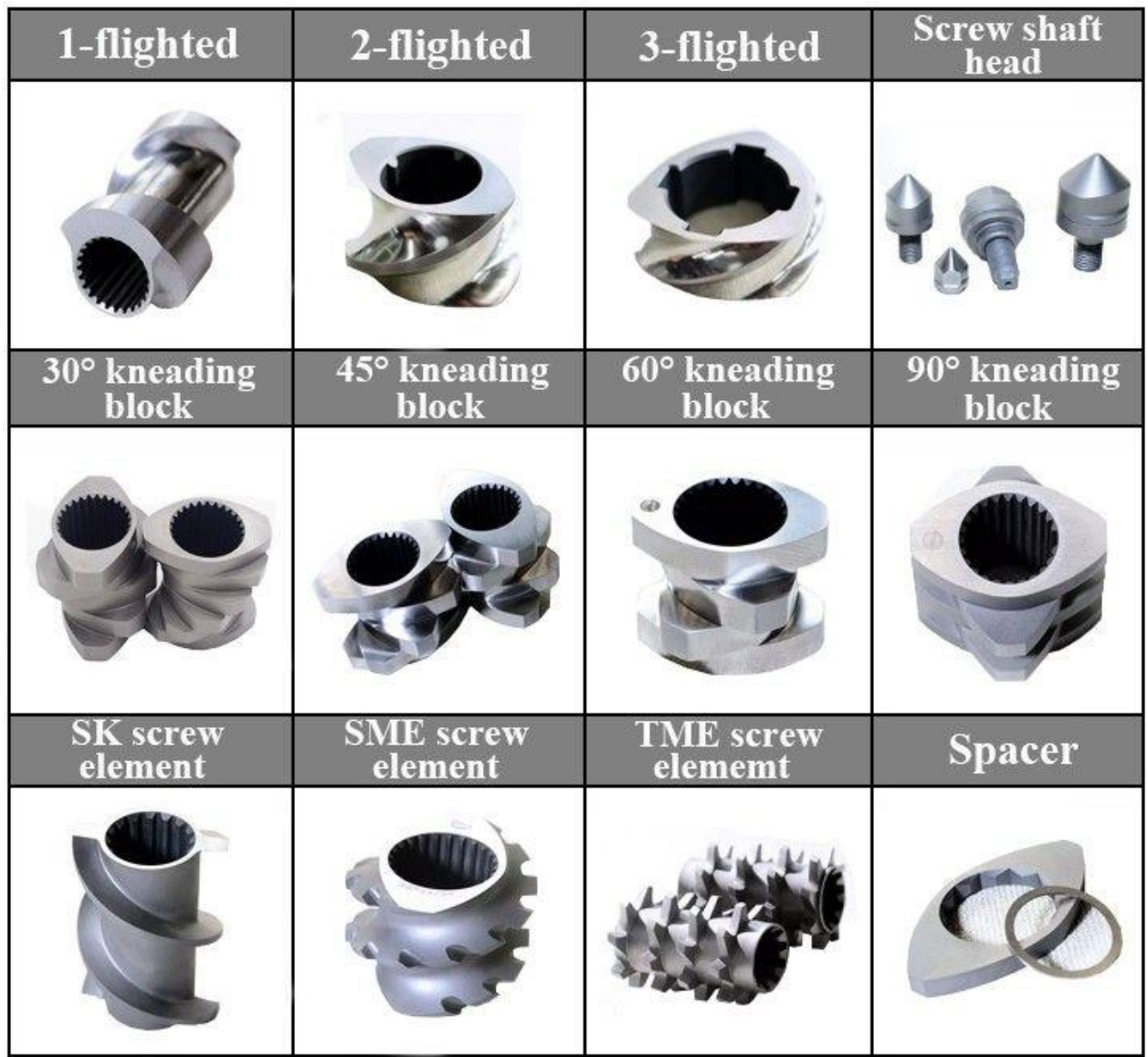

Figure 2 (b):-Different types screw element used in twin screw extruder

The co-rotating intermeshing twin screw extruder has excellent conveying capacity i.e. up to the power limit of the drive motor, the feed rate of material may be varied independently from the screw speed, hence we can control the shear rate and residence time of the process. The operating limits can be changed by changing screw configuration 
(Figure $2 \mathrm{a}, \mathrm{b}$ and $\mathrm{c}$ )

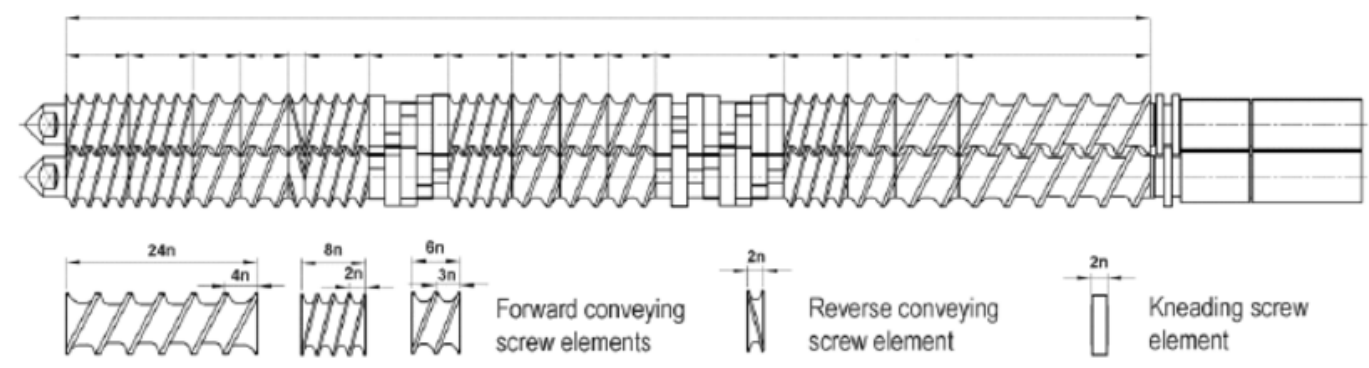

Figure 2 (c):-A representative screw configuration suits for hybrid composit.

The performance of the twin screw extruders is determined by the torque carrying capability and screw free volumes (conveying capacity). In case of low bulk density materials the free volume and feed capacity are more important than installed power, but for high viscosity, shear sensitive polymers the high power at low speed of is of more useful i.e. reducing process temperature.

\section{Conclusion:-}

The development of hybrid composites with natural fibres and nano-materials is just a beginning of a future technology as reinforcements of natural fibres with nano-materials gives synergetic effect. Although the ecological aspects of natural fibres have been the primary reason to consider them as potential materials for the applications like automotive, aerospace, construction, packaging and many other composites based industries.

Some factors of like low density, moisture content, compatabillity of natural fibres with hydrophobic polymer matrix and dispersion of nano-materials and the adhesion of reinforcement with polymers are some limiting factors, which are creating big hindrances in the development of hybrid composites. Cost-effectiveness and consistency in the supply of natural fibres are also a limiting factor faced by researcher involved in the development of hybrid factors.

The reactive melt blending by segmented co-rotating twin screw offers a promising process which suits for the development of the hybrid composites. The segmented barrel and agitator designs allowing the feeding, conveying, mixing, venting and pressure generating regions to be varied to suits the specific requirements of a vast range of polymers and reinforcements. This process offers high level of mixing action at low temperature and friction. The self cleaning and positive conveying characteristics of these extruders ensure a uniform shear profile with a minimum clean time.

The crucial success of future development of hybrid composites based on natural fibres and nano-materials will depends on the understanding of these reinforcement system with proper understanding of melt extrusion by twin screw extruders.

\section{Reference:-}

1. Report on (2017): An analysis of European Plastics, production, demand and waste. By Europe (The Association of Plastics Manufacturers in Europe) and EPRO (The association of Plastics Recycling and Recovery Organisation).

2. Crawfor R.J., (1998): Plastic Engineering, Butterworth Heinemann, Oxford U.K.

3. Uddin N., (2013): Development in Fiber-Reinforced Polymers (FRP) Composites for Civil Engineering , Elsevier

4. Jawaid M., Abdul Khalil H.P.S., "Cellulosic/synthetic fiber reinforced composites polymer hybrid composite: A review" Carbohydrate Polymer, 2011, 86, 1-18

5. Satyanarayana K.G., Arizaga G.G.C., " Biodegradable composites based on lignocellulosic fibers- An overview", Prog. Polym. Sci, 2009, 34, 982-1021

6. Faruk O., Bledzki A.K. Fink H.P., and Sain M.,: "Biocomposites reinforced with natural fibers: 2000-2010". Progress in Polym Sci., 2012, 37, 1552-1596 
7. Dittenber D.B., Ganga Rao H.V.S, "Critical review of recent publication on use of natural fibres composites in infrastructure", Composite A Appl. Sci. Manuf, 2012, 43, 1419-29

8. Sarifuddin N., Ismail H., and Ahmad S.: "Effect of Fibre loading on properties of thermoplastic sago starch/ kenaf core fibre biocomposites". BioResources, 2012, 7(3), 4294-4306

9. Bella G.D., Fiore V., Galtieri G., Borsellino C., and Valenza A., "Effects of natural fibers reinforcement in lime plasters (kenaf and sisl vs Polypropylene". Construction and Building Materials, 2014, 58, 159-165.

10. Arrakhiz F.Z., Achaby M.E., Malha M.,: "Mechanical and thermal properties of natural fibers reinforced polymer composites: doum/low density polyethylene". 2013, 43, 200-205

11. Dahlke B., Larbig H., Scherzer H.D., Poltrock R.,:"Natural Fiber reinforced foams based on renewable resources for automotive interior application". J. Cell. Plast. 1998,34, 361-379

12. Adeosun Sunday. O., Lawal G. I. , Balogun Sambo. A.: "Review of Green Polymers Nanocomposites" Journal of Minerals and Materials Characterization \& Engineering, 2012, 11, 4, 483-514

13. Azeredo De, (2009): "Nanocomposites for food packaging applications". Fppd Res. Int., 2009,42, 1240-1253

14. Schalder L.S., Brinson L.C., Sawyer W.G.,: "Polymer Nanocomposites: A small part of the stroy". JOM, 2007,59, 53-60

15. Aftab A., Bajwa G.S., Ranganath M.S., Mishra R.S., "Recent Development in Polymeric Hybrid Composites: Opportunities and Challenges", Proceedings of ICAPIE 2017, 154

16. Aftab A., Bajwa G.S., Gupta A.P., Ranganath M.S., "Biomaterial Incorporated Polyolefins Nanocomposite: Opportunities in the Automotive Sector", Proceedings of ICAPIE 2016, 424

17. John M., Thomas S.,: "Biofibers and biocomposites." Carbohydr. Polymer,2008.71, 343-364.

18. Saba N., Md. Tahir P., Mohd. Jawaid,: "A Review on Potentiality of Nano Filler/Natural Fiber Filled Polymer Hybrid Composites.”, Polymers, 2014,6, 2247-2273

19. Kalia S., Kaith B., Kaur I., "Pre-treatments of natural fibres and their application as reinforcing material in polymer composites- A review" Polym. Eng. Sci, 2009, 49, 1253-72

20. Mishra S., Mohanty A., Drzal L., Misra M., Parija S., Nayak S., Tripathy S., "Studies on mechanical performance of biofibre/glass reinforced polyester hybrid composites" Composite Sci Technol., 2003, 63, 137785

21. Modern Plastics Encyclopedia handbook, Mcgraw Hill, 1994. 